\title{
El derecho a la protesta social y la critica de la violencia ${ }^{1}$ Por Gabriel Ganon
}

\section{Introducción: Entre el ejercicio de un “derecho” o la comisión de un delito}

Mucho se ha dicho y escrito en términos jurídicos penales y/o sociológicos políticos sobre la criminalización de la protesta social en nuestro país. Sin embargo, muy poco o nada se ha hecho para afinar genealógicamentela investigación y analizar las relaciones complejas que subyacen ese recorte. Para ser claro y simple, la protesta social y su criminalización, no son ni más ni menos, una parte importante del reflujo de la tensión, tan constante como perpetua, entre la violencia, el poder, el derecho y la justicia. Como no podía ser de otra manera esa tensión se agudiza en tiempos de conflicto social o de lucha de clases. Básicamente, esa tensión nos devuelve al inicio de la organización de los estados modernos cuando aquellos monopolizan, se apropian de toda violencia legítima. Recorriendo la historia de ese sinuoso camino relacional entre violencia, fuerza, derecho, justicia, legalidad, legitimidad nos parece oportuno citar a Derrida que afirma “...desde el primer intercambio se anuncian los deslizamientos equívocos entre el derecho y la justicia... el derecho es una fuerza que se justifica o esta justificada al aplicarse pero que puede ser juzgada como injusta o injustificable..." Entonces se pregunta “... ¿Que diferencia existe entre la fuerza de la ley que puede ser justa, en todo caso legítima (no solamente al servicio del derecho sino el ejercicio y el cumplimiento del mismo...y de otra parte la violencia que se juzga siempre injusta? ¿que es una fuerza justa o una fuerza no violenta?...Heidegger se esfuerza en mostrar que la justicia, el proceso, el derecho, el veredicto, la pena o el castigo, la venganza es originariamente conflicto... el cuestionamiento sobre el derecho y sobre la justicia es un cuestionamiento sobre los fundamentos del derecho, la moral y de la política..." (Derrida, 2008:17)

Así las cosas, podría decirse que la discusión en torno a la interpretación estatal que los estados normativamente dan, a través de sus leyes o de sus jueces, a los movimientos sociales de protesta para criminalizarlos o no, transita siempre terrenos laberínticos y pantanosos. Digamos, que no existen señales, ni senderos ni caminos para llegar a destino porque no hay criterio único y seguro de distinción. En términos básicos, equivale a decir como iremos viendo, que la criminalización de la protesta social no es más ni menos que una de las tantas manifestaciones de judicialización de la política o politización de la justicia. Estas expresiones sintetizan las contradicciones implícitas del modelo de estado burgués, modelo en el que el Estado es el único autorizado a ejercer la violencia. Este recurso ideológico, de convertir el conflicto social en un problema judicial no solo que no es nuevo sino que esta dirigido a cuestionar la legitimidad o "justicia” del reclamo. En otras palabras, nunca es posible contestar en forma uniforme a la pregunta: ¿Cuando una protesta social se "ajusta" al ejercicio de un derecho -libertad de expresión, derecho de reunión, de peticionar o de huelga- o constituye delito-entorpecimiento de la

\footnotetext{
${ }^{1}$ Magister/Abogado Gabriel Elías Ganón, Defensor General de Santa Fe, Profesor de Criminología UNR, UNL, UNMDQ
} 
libre circulación, asociación ilícita, resistencia a la autoridad, etc.-? Así las cosas, poco importa que cierto sector de la dogmática penal considere a la protesta social como acto de fuerza/violento justificado/legítimo porque resulta del ejercicio de un derecho que da lugar a una causa de justificación. Importa poco o directamente nada porque en términos generales, los actores institucionales con poder de definición (policías, fiscales y jueces) pueden y de hecho lo han hecho, considerar que la protesta social es un delito. Cuando así lo hacen dan privilegio al derecho al libre tránsito por sobre la libertad de expresión, el derecho de reunión o de peticionar sin considerar la "causa de justificación" de su comisión.

En palabras de Dworkin “...la consecuencia que sí cabe sacar es que cuando las razones prácticas para enjuiciar son relativamente débiles en un caso determinado, o se las puede cumplir de otras maneras, la senda de la equidad pasa por la tolerancia. La opinión popular de que la ley es la ley y siempre se ha de imponer su obediencia, se niega a distinguir entre el hombre que actúa según su propio juicio ante una ley dudosa... y el delincuente común. A no ser por causa de ceguera moral, no sé de otras razones para no establecer entre los dos casos una distinción de principio...me interesa señalar que un tribunal no debe condenar, por lo menos en algunas circunstancias, aún cuando lo respalden las leyes (existentes) y encuentre que los hechos son los que se denuncian..." (Dworkin, 1977).

\section{La Jurisprudencia Argentina en la Criminalización del Derecho a la Protesta}

No es casual que exista en la jurisprudencia argentina el predominio de una línea de pensamiento que cree que los "conflictos sociales" deben ser tratados por el derecho penal. El más claro ejemplo es el famoso caso Schifrin que marco una etapa histórica del surgimiento piquetero argentino (Cámara Federal de Casación Penal, Sala I, causa 3905, registro Nro. 5150). Ese fallo acompaño jurídicamente las respuestas del estado durante la década pasada.

Como podrá recordarse desde el fondo de la descomposición social ocurrida a partir de mediados de la década del 90 aparecieron nuevas formas de organización y movimientismo. El pueblo sacrificado por las políticas neoliberales que arrasaron orgánicamente con miles de puestos de trabajo e ignorado por los medios de comunicación, hizo su irrupción en las rutas del país, impidiendo la libre circulación de personas y mercancías, en demanda de puestos de trabajo.

La proliferación de las protestas en un marco de exclusión social requirió importantes cambios en las formas de intervención social del Estado: por un lado, el Estado fue desarrollando estrategias de contención de la pobreza, por la vía de la distribución -cada vez más masiva $\neg$ de planes sociales y asistencia alimentaria entre las poblaciones afectadas; por el otro, el Estado siguió utilizando el aparato represivo recurriendo a menudo a la criminalización de los grupos sociales mas movilizados.

Como suele ocurrir la mayoría de la administración de justicia prefiere seguir la sintonía fina del gobierno. Así, jueces y fiscales comenzaron a actuar de oficio, abriendo causas penales contra militantes sociales o solicitando investigaciones y seguimientos sobre las modalidades organizativas y financiamientos de determinadas agrupaciones piqueteras. 
En la línea de crítica de la judicialización de los conflictos sociales mediante la utilización del derecho penal como herramienta para zanjar conflictos sociales se expresa Marina Soberano “... los jueces argentinos han utilizado para justificar la criminalización de la protesta, afirmaciones dogmáticas tales como "no existen derechos ilimitados" ...una herramienta útil para el juez que puede fijar ese límite donde mejor le parezca... en el análisis del juego de los derechos (o deberes) remiten a fórmulas en que la libertad de expresión o el derecho a protestar, peticionar ceden ante el bien común, el orden público..." En un sentido opuesto al reseñado dictaminó el Fiscal Javier De Luca citando entre otros muchos argumentos el voto en disidencia del Juez Douglas en el caso "Adderley v. Florida” de la Corte de Estados Unidos de America “... el derecho de petición para reparar agravios tiene una antigua historia y no se limita a la redacción de una cara o el envío de un telegrama a un miembro del congreso, no está limitado a la comparecencia ante el Consejo del municipio local o la redacción de cartas al Presidente, Gobernador o el alcalde. Los métodos convencionales de petición pueden ser y menudo han sido imposibles para nutridos grupos de ciudadanos. Los legisladores pueden hacer oídos sordos, las quejas formales pueden ser desviadas en el laberinto burocrático, los tribunales pueden permitir que las ruedas de la justicia giren muy lentamente. Los que no controlan la televisión, la radio, los que no pueden pagar la publicidad de los periódicos o difundir folletos completos, quizá dispongan a lo sumo de un tipo mas limitado de acceso a los funcionarios públicos. Sus métodos no deben ser condenados como tácticas de obstrucción y presión...” (Dictamen Nro. 10647 “Acosta Josefina s/ entorpecimiento de servicios públicos" Causa N FSM 3884/2013/5/CFC2 Sala 4 FN 97504/2013). Como se advierte la discusión dogmática que está fuera de este ensayo transita por discusiones irresueltas que nos devuelven siempre al origen del problema que hemos planteado.Vale la pena recordar que la protesta social, el conflicto, son parte del juego político en las sociedades democráticas. Sin embargo, los gobiernos prefieren pueblos que no se movilicen, que no reclamen por sus derechos, que no se emancipen. Dice Jacques Ranciere que la "emancipación" es equivalente al pasaje de la niñez a la edad adulta. La protesta social es una característica del modelo burgués que "proclamó libertad, igualdad, fraternidad" sin materializarla. El conflicto existe porque el derecho jamás eliminó la puja de intereses, el conflicto, tan solo lo mediatiza. En ese contexto de conflicto constante a menudo las personas se "emancipan" dejan de ocupar lugares fijos, ya no permanecen en su sitio, en su clase, sino que se mueven para reclamar por sus "derechos". La protesta, como decía, es parte de esa emancipación y esa emancipación implica, nos guste o no, ejercer la protesta o la "violencia". La determinación de los límites de la "protesta", dentro del derecho para que ese ejercicio de la violencia pueda ser calificado como legal, es demasiado sutil para poder definirla previamente. No se puede definir porque la "protesta" implica una ruptura con el orden establecido. Una ruptura espacial y temporal en la que desocupados, trabajadores, jóvenes o estudiantes buscan que sus derechos sean respetados o "conquistar" otros nuevos. El camino de la conquista, del respeto de derechos es de quiebre, de ruptura y de conflicto. Por eso, cuando se habla tanto de la búsqueda del consenso, del diálogo parecería que nos quieren hacer creer que el derecho es, en 
palabras de Nietzche “... la buena voluntad que existe entre quienes son mas o menos igual de poderosos a acomodar sus exigencias para que sean compatibles con las del otro, de llegar a entenderse mediante el equilibrio y en lo que respecta a quienes son menos poderosos, de forzarles a que lleguen a un equilibrio caracterizado por el sometimiento..."

En síntesis, lo que debe tenerse presente es que la definición penalmente reprochable de una manifestación de protesta nunca depende de estándares fijos y determinables. No existe ni un derecho ni una justicia verdadera. Tampoco, un régimen único de presentación e interpretación. Los sentidos de como puede ser tratada, tipificada una protesta social no es patrimonio ni de los jueces ni del gobierno. Es que, en este juego del disenso, de la política, todos y todas somos y debemos ser participes de lo que se percibe, se piensa al respecto y de modificar esos contenidos que no pertenecen con exclusividad a nadie y muchos menos a los jueces, los abogados, los profesores de derecho. No basta con proclamar igualdades o libertades. Hay que luchar por la potencialidad de esas igualdades o esas libertades para que estas se materialicen, que sus efectos se verifiquen. En ese tránsito, insisto, está la disputa por las interpretaciones del reconocimiento de los derechos que hacen o que no hacen quienes tienen el poder de decir el derecho.

\section{Legalidad/Derecho vs. Legitimidad/Justicia de la Protesta Social}

Con un poco mas de precisión crítica podría el marco analítico reducirse a establecer las diferencias para nada sutiles entre "protestas legales" vs. " protestas legítimas". Sin embargo, la contradicción valorativa que existe entre lo que puede eventualmente definirse como legal no necesariamente es siempre coincidente con lo que podría en cada caso considerarse legitimo (obtiene aprobación, consenso) y viceversa.

La reducción terminológica reintroduce la discusión analítica dentro del campo de las caracterizaciones jurídicas y políticas. Decimos que son políticas, no porque exista una contraposición binaria esencial entre lo que es legal y lo que es legítimo, sino porque el concepto de legitimidad esta asociado no solo al poder sino también a lo que es justo. Bajo esas condiciones, en principio habrá protestas legales como "ilegales" y también protestas que declaradas "ilegales" o " criminalizables" sean legitimas o justas. Resumiendo, la declaración de "criminalizable/delictiva" a manifestación social de protesta, por quienes detentan el "poder" o la fuerza del derecho -policías, fiscales y jueces-, solo coloca la protesta por fuera de la ley pero no la vuelve ilegítima e injusta. La facilidad con que suelen confundirse "justicia” con " derecho" o "legal" con "legítimo" ha permitido que los cuestionamientos a esas "decisiones" estatales no sean lo suficientemente precisos. Y no llegan a serlo porque permanece en el imaginario público la idea de que lo que se declara ilegal es equivalente a injusto. Esa perdida de consciencia popular facilita como decía al comienzo la judicialización del conflicto, de la política. En esa línea debe recordarse que el derecho fue, con la revolución burguesa, el envoltorio conceptual de la violencia. Quizás por eso al decir de Pascal “...la justicia sin la fuerza es impotente... y agregaba que “...la fuerza sin la justicia es tiránica...” acusada/desafiada.

En otras palabras, aunque la ley, policías, fiscales o jueces determinen que una protesta es ilegal, que está fuera del derecho, nada se haya resuelto y la discusión sigue tan 
abierta como antes. En adelante para ir verificando hipótesis conviene traer a colación que desde la revolución burguesa en adelante los estados monopolizan toda la violencia legítima ${ }^{2}$. Eso implica en términos del derecho moderno que la personas privadas no pueden ejercer la violencia ni siquiera cuando persiguen un fin justo. En síntesis, monopolizar la violencia legítima implica por un lado, que solo los funcionarios estatales pueden ejercer violencia para hacer cumplir la ley. Por otro lado, que la violencia en manos privadas podría constituir un peligro para el orden legal incluso cuando esa violencia derive del ejercicio de un derecho.

Entonces, el análisis sobre la criminalización de las protestas sociales requiere discutir un poco menos en términos de dogmática penal y por el contrario hacer reaparecer en escena las tensiones de origen que existen y existieron en las relaciones entre el Estado, el Derecho y la Justicia. Esas tensiones son las que no dejan de interpelar sobre la imposibilidad de establecer un criterio seguro para distinguir entre el derecho y la justicia o mejor aún sobre la determinación de la existencia de una fuerza justa o una fuerza no violenta (Derrida, op.cit.). Esto ocurre no solo porque es imposible hablar sin concebir al estado como la necesaria condición del derecho presente, sino porque el estado transforma el ejercicio de la fuerza en un acto normativo.

IV. Walter Benjamin: La critica de la violencia y la protesta social. Argentina: "Semana Trágica” y "asociación ilícita"

En términos benjaminianos, la tensa relación entre lo que es legal y lo que es justo se circunscribe a la tarea de la crítica de la violencia. No por causalidad el berlinés escribía su ensayo en la conflictiva Alemania de la pos guerra (lucha de clases, conflicto,'desorden", etc.) La dura derrota de guerra había derivado en crecientes disputas obreras, escasez de alimentos, desempleo, inflación y alto endeudamiento. En paralelo el reordenamiento de la economía mundial impactaba con dureza en Argentina. En diciembre de 1918 comenzaba una huelga de los 2500 obreros metalúrgicos de los talleres Pedro Vasena e Hijos que se amplificó y terminó con 700 muertos y cerca de 4000 heridos. Pocos años después, en coincidencia con la finalización de la impresión de "Para una Critica de la Violencia” de Walter Benjamin, el Congreso Argentino incluía en el Código Penal el delito de asociación ilícita luego de varios intentos frustrados ${ }^{3}$.

La síntesis del conflicto previo y la respuesta legal demuestran que la tipificación no pretendía otra cosa que poder tener a mano una figura penal que eventualmente sirviese para perseguir disidentes. Por esos motivos, se alegaba que se buscaba lograr la protección del "orden público" el "orden social" la "tranquilidad pública". El tipo penal

\footnotetext{
2 "Estado es aquella comunidad humana que, dentro de un determinado territorio (el "territorio" es elemento distintivo), reclama (con éxito) para sí el monopolio de la violencia física legítima. Lo específico de nuestro tiempo es que a todas las demás asociaciones e individuos sólo se les concede el derecho a la violencia física en la medida en que el Estado lo permite. El Estado es la única fuente del "derecho" a la violencia." (Weber. 2009, pp. 83-84)

${ }^{3}$ Proyecto Piñero, Rivarola, Matienzo de 1891, Proyecto Segovia de 1895, Proyecto 1906 y Proyecto 1917
} 
de asociación ilícita se aprobaba como parte de una estrategia dirigida a "criminalizar" eventuales protestas sociales luego de la sangrienta represión en la conocida "Semana Trágica" de los huelguistas de la metalúrgica Vasena ${ }^{4}$. La historia da cuenta que con esa sanción no se perseguía otra cosa que tener a mano la ley penal para poder perseguir legalmente a los grupos obreros que comenzaban a organizarse. Desde el primer proyecto que contempló la figura, se buscaba incorporar un tipo penal que equiparase el "orden público" con el "orden social". Por esa razón ni los ortodoxos dogmáticos penales logran ponerse de acuerdo sobre el bien jurídico que la norma protege. En su mayoría al analizar la figura argumentan que lo que se busco es proteger la "tranquilidad pública" o peor aún tutelar la inquietud que provocan la mera existencia de estas agrupaciones/sociedades en la tranquilidad del pueblo.

Pero volvamos al ensayo de Benjamin porque todavía no puede advertirse la relación que pretendo remarcar. Según Benjamin una acción es violenta cuando incide sobre relaciones morales. La esfera de esas relaciones es definida por los conceptos de derecho y justicia. La violencia solo puede ser buscada en un ordenamiento jurídico en los medios, nunca en los fines. En ese contexto aún cuando la protesta social traduzca el ejercicio de un derecho es un acto en principio violento. De todas maneras, como en el caso del ejercicio del derecho de huelga, el derecho a la protesta, no puede etiquetarse sin más como violento. Igual, casi siempre le queda al Estado a través de su policía, jueces o fiscales, la posibilidad de definir la protesta como el uso abusivo de un derecho. Esta opción con la que cuentan las autoridades estatales no es ninguna casualidad porque la distinción de interpretación ejemplifica la contradicción práctica del estado de derecho (Benjamin, 1998:26).

Así, como siempre ocurre, bajo ciertas condiciones y aunque parezca paradojal un comportamiento puede resultar "ilegal" "criminalizable" "violento" aún cuando surja del ejercicio de un derecho. Por tal motivo, al decir de Eligio Resta debe ponerse nuevamente al descubierto “... las huellas ya cubiertas de polvo y bien escondidas de la relación entre soberanía y violencia...” (Resta, 1995: 102). En esa línea Benjamin resalta con maestría inigualable como luego de una revolución se crean nuevas condiciones políticas que se reflejan en un nuevo orden jurídico. Por eso, todo el nuevo aparato de ejercicio del monopolio de la violencia que se construyo con los estados modernos del siglo XVIII (leyes, parlamentos, policías, jueces, etc.) no fueron formas mas emancipadoras de lidiar con el conflicto sino el resultado de toda una transformación política. Ese nuevo orden político estatiza/formaliza la idea "justicia”, se apropia de la violencia y se arroga con exclusividad el poder de castigar. Por eso el delito no es delito por lo que moralmente o

\footnotetext{
${ }^{4}$ La Semana Trágica fue el final de la huelga obrera que había comenzado en diciembre de 1918 en los talleres metalúrgicos Pedro Vasena e Hijos. La industria metalúrgica afectada por la primera guerra buscaba bajar costos. Los obreros pretendían mejoras en sus salarios, jornadas de ocho horas, horas extras, etc. Esta huelga pronto derivo en una sangrienta represión que terminó con 700 muertos y cerca de 4000 heridos.
} 
esencialmente signifique sino que es delito porque "ataca" al estado, desafía sus derechos y su voluntad.

\section{La nueva coyuntura política argentina. El Protocolo Antipiquetes y el Fallo Orellano}

En este sentido, más allá de la mayoritaria jurisprudencia existente, en la Argentina actual se produjeron dos hechos políticos relevantes dirigidos a "precisar" desde el poder cuando una protesta social puede ser "legal" o "ilegal".

Sin embargo, aunque explícitas esas "decisiones" pretenden borrar de la memoria el origen de su "soberanía/investidura". Así, el derecho a la protesta o a la huelga que no son más ni menos que el ejercicio "autorizado" del derecho a la violencia pueden ser inmediatamente limitados, criminalizables por el estado que decide cuando ese derecho se autoriza o no. Para Benjamin aunque los trabajadores y/o los manifestantes de un piquete podrían escudarse en el ejercicio del derecho a libertad de expresión, peticionar y/o huelga, el Estado siempre retiene la posibilidad de considerarlo un abuso de derecho. En esa línea se dictó el Protocolo Antipiquetes del Ministerio de Seguridad de la Nación. Una explicita declaración de principios poco democráticos. Así, enumerando en forma confusa y como valores equivalentes a la preservación del orden, el bienestar general, la propiedad privada y la seguridad jurídica, proclama en tono castrense que toda manifestación se puede convertir, por decisión unilateral del jefe del operativo, en un delito flagrante ${ }^{6}$. En un sentido similar la Corte Suprema de Justicia limito con "razón" en el

${ }^{5}$ En diario Página 12 del Domingo 28 de agosto de 2016. La periodista Laura Vales tituló: "Menos trabajo mas conflictividad". Su nota se apoya en un relevamiento del Centro de Economía Política Argentina que registro 99 conflictos laborales durante el mes de julio con protestas en el sector privado y público. Continúa enumerando casos paradigmáticos recientes: la represión en julio en Ledesma (Jujuy) y las de agosto, el 11 al piquete CTD Aníbal Verón en Mar del Plata previo al discurso del Presidente Macri; el 16 a jubilados en la autopista Buenos Aires-La Plata y el 24 en el Tabacal (Salta) http://www.pagina12.com.ar/diario/elpais/1-307953-2016-08-28.html.

6 "...Que es deber del Estado asegurar el orden público, la armonía social, la seguridad jurídica, y el bienestar general, por ello ante la alteración del ejercicio equilibrado de derechos, debe lograr su inmediato restablecimiento a los fines de garantizar la libertad de todos; para ello debe brindar certezas respecto del accionar de las FFSS ante la situación de manifestaciones en la vía pública y, garantizar que ante tal situación, los derechos de la ciudadanía en general, del personal de las FFSS y de los manifestantes, se encuentren protegidos por el Estado, preservando la libertad, la vida, integridad física, y bienes de las personas, así como el patrimonio público y privado que pueda verse afectado con motivo u ocasión de la manifestación... “... el Jefe del Operativo impartirá la orden a través de altoparlantes, megáfonos o a viva voz, que los manifestantes deben desistir de cortar las vías de circulación de tránsito, deberán retirarse y ubicarse en zona determinada para ejercer sus derechos constitucionales, garantizando siempre la libre circulación. Se advertirá que ante el incumplimiento de dicha instrucción, se encontrarán incursos en el artículo 194 del Código Penal, y en su caso, en las contravenciones 
abuso de derecho la huelga en el caso Orellano ${ }^{7}$. El fallo no solo limita en forma explícita el derecho a huelga a los sindicatos reconocidos, sino que además declara la "ilegitimidad" de medidas de fuerza promovidas por grupos informales. No solo resulta curiosa la decisión porque declara que la Constitución Nacional y los tratados internacionales de derechos humanos le reconocen el derecho a huelga con exclusividad a los sindicatos, sino que pretende circunscribir lo justo, lo legítimo dentro del derecho positivo en forma arbitraria. La valoración que realiza la Corte al definir la huelga como una violencia dentro del derecho, como un medio de presión, para lograr ciertos fines, también se arroga la posibilidad de definir el cómo, el cuándo y el donde esos fines colisionan con el poder del estado.

Resumiendo, ambos hechos ponen en negro sobre blanco no solo las contradicciones prácticas del estado de derecho sino también expresan con claridad que no habrá demasiado espacio para que ese orden pueda ser discutido o amenazado bajo el tradicional marco del ejercicio del derecho a la protesta, la huelga o la libertad de expresión. Nada más que por eso se puede entender que la línea que separa la posibilidad de criminalizar una protesta social es mucho mas sutil de lo que parece y de lo que suele decirse.

Nótese que, en especial, el fallo de la Corte consagra el fundamento místico de la autoridad al confundir la justicia/legitimidad del reclamo con los medios empleados. De esta manera, se cierra la discusión sobre los fines justos o legítimos del ejercicio de la violencia a través del derecho a huelga en particular o de cualquier otro.

\section{El Derecho a la Protesta y el Sistema Internacional de Derechos Humanos}

Ambas decisiones, el Protocolo Antipiquetes y el fallo Orellano van a contramano de los estándares internacionales de derechos humanos. En el derecho internacional de los derechos humanos la protesta social constituye una forma central de petición a la auto-

previstas en cada jurisdicción. Si los manifestantes no cumplieren con la orden recibida, se les solicitará que depongan el corte bajo apercibimiento de proceder conforme lo establecido para los casos de los delitos cometidos en flagrancia... " http://www.minseg.gob.ar/pdf/protocolo-final.pdf

${ }^{7}$ Francisco Orellano fue despedido y luego reincorporado del Correo en el año 2009 tras participar de medidas de fuerza que no habían sido convocadas formalmente por un sindicato. La empresa justificó la decisión de despedirlo por considerar que esas actividades afectaban el desarrollo normal de su actividad en el centro operativo de Montegrande. Orellano reclamó la nulidad de la medida porque consideró que su despido era en represalia a su participación en actividades gremiales. La Sala I de la Cámara Nacional de Apelaciones del Trabajo admitió la demanda del trabajador y sostuvo que sus actividades "se hallaban dirigidas a la obtención de mejoras de salarios y contaban con la presencia de un número importante de personal”. Sin embargo, la Corte Suprema de Justicia revocó el fallo de la Sala I. Los magistrados concluyeron que las medidas de fuerza no eran legítimas y basándose en el artículo 14 bis de la Constitución Nacional y normas internacionales, consideraron que el derecho de huelga solo puede ser ejercido por asociaciones sindicales con personería gremial y por los sindicatos simplemente inscriptos. 
ridad, una de las formas colectivas más eficaces de expresión ${ }^{8}$ y un canal de denuncias sobre vulneraciones o violaciones de derechos humanos ${ }^{9}$. Ambos derechos son componentes esenciales de un funcionamiento inclusivo del sistema democrático ${ }^{10}{ }^{11}$. No es novedoso que se afirme, siguiendo los pronunciamientos de los distintos organos del sistema internacional de derechos humanos, que existe un fuerte vínculo entre el derecho a la protesta y los derechos de libertad de expresión, asociación ${ }^{12}$ y participación en los asuntos públicos ${ }^{13}$. El pleno disfrute y respeto de la libertad de realizar protestas y manifestaciones públicas, al igual que la libertad de criticar o de oponerse al gobierno, es parte de la libre circulación de ideas e información acerca de las cuestiones públicas y políticas. ${ }^{14}$ Esta asociación de derechos se muestra especialmente fuerte en escenarios

${ }^{8} \mathrm{CIDH}, 2010$ Una agenda hemisférica para la defensa de la libertad de expresión, pár. 69. En el "Informe Anual de la Relatoría para la Libertad de Expresión 2002" se establece: "En muchos países del hemisferio, la protesta y movilización social se ha constituido como herramienta de petición a la autoridad pública y también como canal de denuncias públicas sobre abusos o violaciones a los derechos humanos".

${ }^{9}$ CIDH, Informe de la Relatoría para la Libertad de Expresión, 2005, cap. V, "Las Manifestaciones como Ejercicio de la Libertad de Expresión y la Libertad de Reunión”, pár. 1

${ }^{10} \mathrm{CIDH}$, Informe sobre la Situación de las Defensoras y Defensores de los Derechos Humanos en las Américas, 2006, pár. 55. La Relatoría subraya que la participación de las sociedades a través de la manifestación pública es importante para la consolidación de la vida democrática de las sociedades. En general, ésta como ejercicio de la libertad de expresión y de la libertad de reunión, reviste un interés social imperativo... CIDH, Informe de la Relatoría para la Libertad de Expresión, 2005, cap. V, "Las Manifestaciones como Ejercicio de la Libertad de Expresión y la Libertad de Reunión”, pár. 91.

${ }^{11}$ El derecho a la protesta social y a participar en manifestaciones públicas deriva del reconocimiento de un conjunto de otros derechos contemplados en las Convenciones, entre los cuales se incluyen el derecho a la libertad de expresión ${ }^{11}$, el derecho de reunión y la libertad de asociación ${ }^{11}$, los derechos sindicales y el derecho a la huelga ${ }^{11}$ y el derecho de participación en los asuntos públicos ${ }^{11}$. En el ámbito del Sistema Interamericano, el reconocimiento del derecho a la protesta y a participar en manifestaciones se deriva principalmente de los artículos 4 y 21 de la Declaración Americana de los Derechos y Deberes del Hombre y en los artículos 13 y 15 de la Convención Americana sobre Derechos Humanos, que reconocen el derecho a la libertad de expresión y el derecho de reunión. En este sentido, esta Comisión ha señalado que el intercambio de ideas y reivindicaciones sociales como forma de expresión supone el ejercicio de derechos conexos, entre los cuales se encuentra el derecho de los ciudadanos a reunirse y a manifestar, y el derecho al libre flujo de opiniones e información.

${ }^{12}$ Reconocido en el artículo 22 de la Declaración Americana de Derechos y Deberes del Hombre y 16 de la Convención Americana de Derechos Humanos.

${ }^{13}$ Reconocido en el artículo 20 de la Declaración Americana de Derechos y Deberes del Hombre y 23 de la Convención Americana de Derechos Humanos.

${ }^{14}$ CIDH, Informe de Seguridad Ciudadana y Derechos Humanos, 2009, pár.192; CIDH, In- 
de desigualdad estructural. La Relatoría de Libertad de Expresión ha manifestado que los sectores más empobrecidos de nuestro continente confrontan políticas y acciones discriminatorias. En ese contexto los canales tradicionales de participación a los que deberían acceder para hacer públicas sus demandas se ven muchas veces cercenados .${ }^{15}$ Por eso, la participación política y social a través de la manifestación pública reviste para la Comisión un interés social imperativo que deja al Estado un marco ceñido para justificar una limitación a este derecho. ${ }^{16}$ No se puede considerar el derecho de reunión y manifestación como sinónimo de desorden público para restringirlo per $\mathrm{se}^{17}$ La protesta social es no solo parte, sino esencial para la consolidación de la vida democrática. Esa relevancia obliga a los Estados además de no restringirla ni criminalizarla a realizar acciones concretas que la faciliten. En este sentido, de acuerdo con la $\mathrm{CIDH}$, la protección del derecho de reunión comporta no sólo la obligación del Estado de no interferir con su ejercicio, sino también el deber de adoptar, en y ante ciertas circunstancias, medidas positivas para asegurarlo. ${ }^{18}$

\section{Conclusión}

Un breve repaso por la historia exhibe con claridad que a medida que se intensifican las protestas sociales crece la tensión y contradicción del modelo de estado de derecho. Esas circunstancias no pueden ser pasadas por alto en una coyuntura como la actual en la que ha caído ostensiblemente el poder adquisitivo de los salarios y comienza a crecer aceleradamente el desempleo. Esas circunstancias hacen previsible un escenario de conflictos sociales creciente como lo planteamos al comienzo. En esa coyuntura se verá hasta que punto la huelga, la protesta, el piquete pueden modificar las condiciones de "derecho" o derivan en represión o criminalización. Como se decía Benjamin "la violencia no se practica ni se tolera ingenuamente" depende la solución de la correlación de fuerzas en la disputa. En esa línea vale la pena citar algunos párrafos de la Carta

forme sobre la Situación de las Defensoras y Defensores de los Derechos Humanos en las Américas, 2011, pár. 133.

${ }^{15} \mathrm{CIDH}$, Informe de la Relatoría para la Libertad de Expresión, 2005, cap. V, "Las Manifestaciones como Ejercicio de la Libertad de Expresión y la Libertad de Reunión”, pár. 1.

${ }^{16} \mathrm{CIDH}$, Informe Anual de la Relatoría de Libertad de Expresión, 2005, cap. V, pár.91; CIDH, Informe sobre la Situación de las Defensoras y Defensores de los Derechos Humanos en las Américas, 2006, pár. 60 .

${ }^{17}$ CIDH, Informe Anual de la Relatoría de Libertad de Expresión, 2005, cap. V, pár.91; CIDH, Informe sobre la Situación de las Defensoras y Defensores de los Derechos Humanos en las Américas, 2006, pár. 60. La Relatoría Especial para la Libertad de Expresión ha señalado que la apelación al mantenimiento del orden público no puede servir como medio para suprimir un derecho garantizado por la Convención o para desnaturalizarlo o privarlo de contenido real. CIDH, Informe Anual de la Relatoría de Libertad de Expresión, 2005, cap. V, pár.92.

${ }^{18} \mathrm{CIDH}$, Informe de Seguridad Ciudadana y Derechos Humanos, 2009, pár.192; CIDH, Informe sobre la Situación de las Defensoras y Defensores de los Derechos Humanos en las Américas, 2011, pár. 133. 
Abierta de Rodolfo Walsh a la Dictadura Militar. “... En la política económica de ese gobierno debe buscarse no sólo la explicación de sus crímenes sino una atrocidad mayor que castiga a millones de seres humanos con la miseria planificada. En un año han reducido ustedes el salario real de los trabajadores al 40\%, disminuido su participación en el ingreso nacional al 30\%, elevado de 6 a 18 horas la jornada de labor que necesita un obrero para pagar la canasta familiar, resucitando así formas de trabajo forzado que no persisten ni en los últimos reductos coloniales. Congelando salarios a culatazos mientras los precios suben en las puntas de las bayonetas, aboliendo toda forma de reclamación colectiva, prohibiendo asambleas y comisiones internas, alargando horarios, elevando la desocupación al récord del 9\%, prometiendo aumentarla con 300.000 nuevos despidos, han retrotraído las relaciones de producción a los comienzos de la era industrial, y cuando los trabajadores han querido protestar los han calificado de subversivos, secuestrando cuerpos enteros de delegados que en algunos casos aparecieron muertos, y en otros no aparecieron. Los resultados de esa política han sido fulminantes. En este primer año de gobierno el consumo de alimentos ha disminuido el 40\%, el de ropa más del 50\%, el de medicinas ha desaparecido prácticamente en las capas populares..."

En estos tiempos no idénticos pero de conflictos que se avecinan es necesario tener presente que es necesario comprometernos con hacer aparecer significaciones nuevas sobre el derecho, sobre la justicia, sobre la ley haciendo estallar la antigua realidad poniendo el dedo en las ficciones, contradicciones disfrazadas. En cierta medida la angustia que sienten las nuevas elites que se traducen en las decisiones citadas expresan en palabras de Ranciere, la angustia que sienten las clases dominantes se vincula con la creciente posibilidad de reconfiguración del mundo porque cada día que pasa se hace mas dificil mantener las apariencias de régimen unico de presentación e interpretación de lo dado que imponga a todos su evidencia. Así, toda situación es susceptible de ser hendida de su interior, reconfigurada bajo otro régimen de percepción y de significación. El disenso pone nuevamente en juego al mismo tiempo la evidencia de lo que es percibido, pensable y factible y el reparto de aquellos que son capaces de percibir, pensar y modificar las coordenadas del mundo común. Parte de ese espacio es el de la protesta social. Tanto Ranciere como Foucault distinguen entre policía y política. Cuando hablan de policía no hablan del organismo represor sino como el "orden" que determina la ley y el Estado. Ese orden asigna a cada cual, a cada grupo social un lugar dentro una estructura que en si misma no es política. La protesta social, el conflicto, la huelga, implica que ciertos actores se movilicen, se desclasifiquen por considerarse perjudicados por la tipificación, que no es más que la clasificación que de ellos hace o intenta hacer el estado. Cuando quienes protestan se desclasifican quieren hacerse escuchar, reclaman otro lugar, ese otro lugar en ser escuchados sin mengua, no ya mediados sino directamente reclamando otro estatuto para sí, reivindicando su igualdad. Una comunidad justa es una comunidad que no requiere de la mediación sino que está en todas las acciones que la comprometen. Nos hace falta otra justicia, una en la que las relaciones de sus palabras, procedimientos, conceptos sean redefinidos, reconcebidos. Hay que construir una nueva justicia a partir de esa energía popular o mejor aún una justicia devuelta a su 
virtud original. Derecho/Justicia sin espectadores. Todos deben ser participantes activos de las definiciones. En definitiva la discusión sobre el carácter que le damos en términos jurídicos a la protesta social pasa más bien por un nuevo examen de sus conceptos y de sus procedimientos, de su genealogía y de la manera en que se han entrelazado con la lógica de la emancipación social.

\section{Bibliografía}

Benjamin, Walter (1998) Por una crítica de la violencia y otros ensayos. Taurus, Barcelona Derrida, Jaques (1997) Fuerza de Ley. Tecnos, Madrid.

Dworkin, Ronald (1977) Tomando los Derechos en Serio. Ariel, Barcelona

Ranciere, Jaques (1996) El desacuerdo. Política y filosofía. Nueva Visión, Buenos Aires (2008) El espectador emancipado. Manantial. Buenos Aires

Roman, Madeline (2006) Estallidos:polisemia y polimorfia del derecho y la violencia. Publicaciones puertoriqueñas.

Weber, Max (2009) La política como vocación. Alianza Editorial, Madrid 